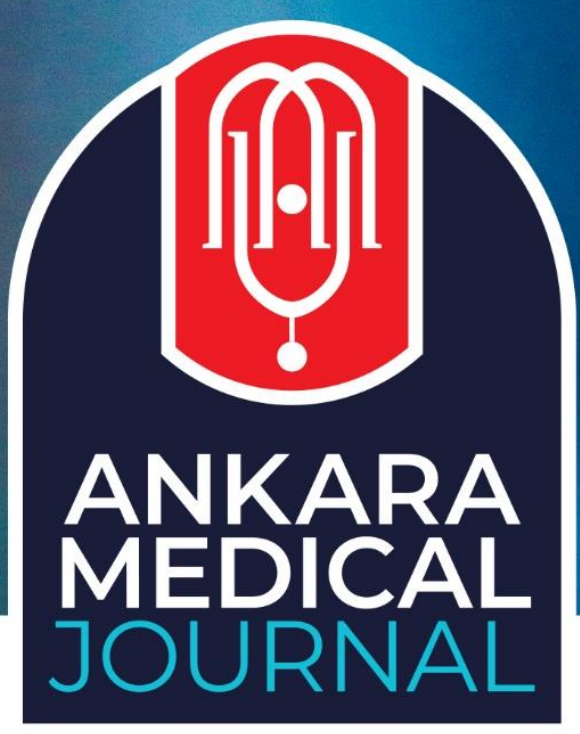

Araștırma Makalesi

Ankara Med J, 2020;(4):1016-1026 // 10.5505/amj.2020.39112

\author{
AİLE HEKIMMLERİNIN ALT EKSTREMİTE \\ OSTEOARTRITLERINDE KULLANILAN \\ NONFARMAKOLOJİK TEDAVI YÖNTEMLERİNE \\ YAKLAŞIMLARI: KESİTSEL BİR ÇALIŞMA
}

\title{
APPROACH OF FAMILY PHYSICIANS TO NONPHARMACOLOGICAL TREATMENT METHODS USED IN LOWER EXTREMITY OSTEOARTHRITIS: A CROSS- SECTIONAL STUDY
}

\section{Sabri Onur Özden ${ }^{1}$, (D) Tarık Eren Yılmaz ${ }^{1}$}

1Sağlık Bilimleri Üniversitesi, Ankara Şehir Hastanesi, Aile Hekimliği Kliniği, Ankara

Yazışma Adresi / Correspondence:

Dr. Öğr. Üyesi Tarık Eren Yılmaz (e-posta: tarikeren.yilmaz@sbu.edu.tr)

Geliş Tarihi: 10.11.2020 // Kabul Tarihi: 26.11.2020

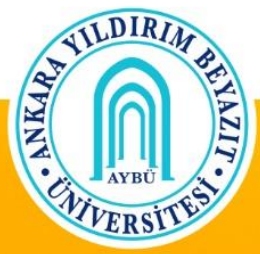

Ankara YIIdrrm Beyazıt University Faculty of Medicine Department of Family Medicine 


\title{
Öz
}

Amaç: Osteoartrit (OA), dünyada en yaygın görülen eklem hastalığıdır, en sık alt ekstremitede görülür ve kronik kas iskelet sistemi ağrılarının en önemli nedenidir. OA tedavisi ve yönetimi amacıyla yayınlanan tüm kılavuzlarda önerilen en uygun tedavi yöntemi farmakolojik ve nonfarmakolojik tedavinin birlikte kullanılmasıdır. Bu çalışmada, Ankara'daki Aile Hekimliği Kliniklerinde çalışan hekimlerin OA tedavisindeki nonfarmakolojik yöntemler hakkındaki farkındalıklarının ve yaklaşımlarının değerlendirilmesi amaçlanmıştır. Materyal ve Metot: Araștırmamız tanımlayıcı, kesitsel tipte bir araștırmadır. 2019 yılı itibari ile Ankara'daki Aile Hekimliği Kliniklerinde çalışan çeşitli unvanlara sahip tüm aile hekimleri çalışma evrenimizi oluşturmaktadır. Katılmaya gönüllü olan aile hekimlerine, anket yüz yüze anket uygulama yöntemiyle uygulanmıştır. Nonfarmakolojik tedavi yaklaşımlarına dair hem kendi yetkinlik kanaati puanları hem de toplam yaklaşım puanları hesaplanmıştır. İstatistiki anlamlılık düzeyi $\mathrm{p}<0.05$ olarak alınmıştır.

Bulgular: Çalışmamıza 234 aile hekimi dahil edilmiştir. Hekimlerin \%54,71'u daha önce OA tedavi yaklaşımları konusunda herhangi bir eğitim almadıklarını belirtmiştir. Eğitim alan ve bu eğitimin yeterli olduğunu düşünen hekimlerin hem nonfarmakolojik toplam yaklaşım puanı hem de kendilerine verdikleri yetkinlik puanları anlamlı olarak daha yüksek olarak saptanmıştır.

Sonuç: OA tedavi yaklaşımları konusunda genel olarak bir eğitim eksikliği saptanmış ve bu konuda daha önce eğitim alıp bu eğitimi yeterli bulan aile hekimlerinin ise bu eğitimlerden faydalandığı bu çalışmada görülmüştür. Maliyet etkin ve uygulaması kolay olan, hastalığın progresyonunu yavaşlatan, engelliliği azaltan nonfarmakolojik tedavi yöntemlerinin aile hekimleri tarafından daha sık kullanılması gerekmektedir.

Anahtar Kelimeler: Aile Hekimliği, osteoartrit, kalça ve diz osteoartriti, nonfarmakolojik yaklaşım.

\begin{abstract}
Objectives: Osteoarthritis $(\mathrm{OA})$ is the most common joint disease in the world, most common in the lower extremities, and the leading cause of chronic musculoskeletal pain. In all guidelines published on the treatment of $\mathrm{OA}$, the most suitable method of treatment is the combination of pharmacological and nonpharmacological treatment. The aim of this study is to evaluate the awareness and approaches of nonpharmacological methods of OA treatment of physicians who working in Family Medicine Clinics in Ankara.

Materials and Methods: This research is descriptive and cross-sectional. As of 2019, all family physicians working in Family Medicine Clinics in Ankara constitute the study population. Family physicians who volunteered to participate in the study were accepted to this study by using face to face survey methods. Both self-efficacy scores and total approach scores for non-pharmacological treatment were calculated. The significance level was taken $\mathrm{p}<0.05$.

Results: 234 family physicians participated to the study. $54.71 \%$ of physicians stated that they had not received a training on OA treatment approaches before. Physicians who received training and thought that this training was sufficient, both the non-pharmacological approach score and the competence scores they gave themselves were found to be significantly higher.

Conclusion: A lack of education on OA treatment approaches was detected and it was seen in this study that family physicians who had received training on this subject and found this training sufficient benefited from these trainings. This study showed that nonpharmacological treatment methods should be used more frequently by family physicians because of easy to apply, low cost and reduce disease progression and disability.
\end{abstract}

Keywords: Family Medicine, osteoarthritis, hip and knee osteoarthritis, nonpharmacological treatment. 


\section{Giriş}

Osteoartrit (OA), dünyada en yaygın görülen eklem hastalığıdır ve kronik kas iskelet sistemi ağrılarının en önemli nedenidir. $\mathrm{OA}^{\prime}$ nın en sık görüldüğü eklemler diz ve kalça gibi yük taşıyan eklemlerdir. ${ }^{1}$

Yaşlı popülasyonda OA' ya bağlı engellilik durumu kardiyak hastalıklar kadar yüksek bir orana sahiptir. Dünya Sağlık Örgütü' nün raporlarında diz OA' nın kadınlarda en sık dördüncü, erkeklerde en sık sekizinci engellilik nedeni olduğu bildirilmiştir. ${ }^{2}$

OA, basit bir kıkırdak rahatsızlığı veya diz eklemi yıpranması değildir. Aynı zamanda OA, sadece ilaçla tedavi edilebilen bir hastalık da değildir. OA, bireysel ve çevresel etkenlerin etkilediği multifaktöriyel etyolojili bir hastalıktır. Dolayısıyla OA tedavi yönetimi de çok yönlü, çok bileşenli ve bireye özgü olmalıdır. ${ }^{3}$

OA tedavisi ve yönetimi amacıyla yayınlanan tüm kılavuzlar tedavinin anahtar prensipleri ve temel tedavi seçenekleri konusunda hem fikirdir. Kılavuzlarda önerilen diz ve kalça OA hastalarında en uygun tedavi yöntemi farmakolojik ve nonfarmakolojik tedavi modalitelerinin birlikte kullanılmasıdır. Hatta nonfarmakolojik tedavi modalitelerinin, OA tedavisinin daha merkezinde yer aldığı ifade edilmektedir. ${ }^{4}$

Opsiyonel farmakolojik tedavinin yanı sıra, hastaların eğitimi, yaşam biçimi değişiklikleri, kilo verme, koruyucu veya engelleyici önlemler, egzersiz ve cihazlama gibi rehabilitatif yaklaşımları içeren nonfarmakolojik yöntemlerin biri veya birkaçının beraber kullanılması gerekliliğinin ${ }^{4}$ bütüncül yaklaşımı ve koruyucu hekimliği benimseyen aile hekimlerince bilinmesi ve bu konu hakkındaki uygulamaları hastalarına önermesi ve hastalarının takiplerini bu kriterlere göre yapması yerinde olacaktır. Dolayısıyla bu konunun aile hekimlerince bilinmesi ve yetkinliğinin artırılması hem birey sağlığı açısından hem de toplum sağlığı açısından önemlidir. Bunun için de ilk olarak aile hekimlerinin bu konu hakkındaki son durumlarını araştırılması uygun olacaktır.

Bu bilgiler ışığında bu çalışmamızda Ankara'daki Aile Hekimliği Kliniklerinde çalışan aile hekimlerinin OA tedavisindeki nonfarmakolojik yöntemler konusunda tedavi yaklaşımlarını değerlendirmeyi ve hekimlerin bu yöntemler hakkındaki farkındalıklarını arttırmayı amaçladık. Ayrıca bu farkındalık artışı sayesinde OA nedeniyle aile hekimlerine başvuran hastaların yaşam kalitesinin (minimum maliyet ve tıbbi yan etkiyle: maliyet etkin bir yöntemle) artırılmasının sağlanmasına ve başvuran hastaların gereksiz çoklu ilaç kullanımının azaltılmasına da katkı sunmayı hedefledik. 


\section{Materyal ve Metot}

Araştırmamız tanımlayıcı, kesitsel tipte bir araştırmadır. Araştırmamıza katılmaya gönüllü olan aile hekimlerine Aralık 2019 - Ocak 2020 tarihleri arasındaki 2 aylık süre içinde anket çalışması uygulanmıştır.

Araştırmanın evrenini Ankara'daki Aile Hekimliği Kliniklerinde çalışan çeşitli unvanlara sahip (öğretim üyesi, eğitim görevlisi, aile hekimliği uzmanı, tam ve yarı zamanlı aile hekimliği asistanı) tüm aile hekimleri oluşturmaktadır. Araştırmanın tüm evrenine (n:400) ulaşıldığında araştırmaya son verilmesi planlanmıştır.

Çalışmaya özgün yapılandırılmış anket, araştırmacı tarafından Ankara'daki Aile Hekimliği Kliniklerinde çalışan aile hekimlerine ilgili kliniklerin eğitim günlerinde gidilerek yüz yüze anket uygulama yöntemi ile doldurtulmuştur. Ulaşılan hekimlerden 247 tanesi anketi doldurmayı kabul etmiştir. Ancak 234 tane anket tam olarak doldurulmuş ve tamamlanmayan 13 anket hariç tutulma kriterleri gereği çalışma dışı bırakılmıştır.

Çalışmada kullanılan ve araştırmacılar tarafından yapılandırılıp hazırlanan anket toplam 23 sorudan oluşmaktadır. Bu sorularda sosyodemografik ve mesleki özellikler, OA teşhisi konulan yakınlarının varlığı, OA ile ilgili eğitim alma durumları, hekimlerin $\mathrm{OA}$ tedavisi ile ilgili literatür bilgileri ve $\mathrm{OA}$ tanısı koydukları hastalarına genel yaklaşımları sorgulanmıştır. Ayrıca hekimlerin kendilerini OA yönetimi konusunda ne kadar yetkin ve donanımlı hissettiklerine dair kendilerine verecekleri 0 ile 10 puan arasındaki bir değerle kendi kanaatlerini bildirmeleri istenmiștir. Son olarak toplam $\mathrm{OA}^{\prime}$ lara yaklaşım puanını veren 12 soruluk alt ekstremite osteoartritlerinde kullanılan nonfarmakolojik tedavi yöntemlerine dair parametreler sorulmuş ve 5'li likert tarzında cevapları alınmıştır. Bu sorulara "hiçbir zaman" cevabını verenler 0, "nadiren" cevabını verenler 1, "ara sıra" cevabını verenler 2, "genellikle" cevabını verenler 3, "her zaman" cevabını verenler 4 puan almıştır. Alınan puanın yüksek olması hekimlerin nonfarmakolojik tedavi yöntemlerini daha sık, düşük olması ise daha az kullandıkları anlamına gelmektedir. Bu şekilde toplam 12 sorudan alınabilecek en düşük puan 0, en yüksek puan ise $48^{\prime}$ dir.

\section{Etik Onay}

Araştırma için yerel hastane Klinik Araştırmalar Etik Kurulu'ndan 06.09.2018 tarihinde 2199/2018 no' lu karar ile onay alınmıştır. Ayrıca gönüllü katılımcılardan yazılı bilgilendirilmiş onamları alınmıştır.

\section{İstatistiksel Analiz}

Veriler IBM SPSS Statistics 18 (c) Copyright SPSS Inc. 1989, 2010 yazılımı kullanılarak analiz edilmiştir. Sürekli değişkenlerin normal dağılıma uygunluğu Kolmogorov-Smirnov testi ile incelenmiştir. Çalışmada yer alan kategorik değişkenler frekans ve yüzde ile sürekli değişkenler ortalama, standart sapma, ortanca, en küçük ve 
en büyük değerleriyle sunulmuştur. Kategorik değişkenlerin analizinde Ki-kare ve Fisher Ki kare anlamlılık testleri kullanılmıştır. Sürekli değişkenlerin analizinde parametrik test varsayımları sağlanmadığı için iki grup ortalama karşılaştırmalarında Mann Whitney U, ikiden fazla grup ortalama karşılaştırmalarında Kruskal-Wallis testi kullanılmıştır. Sürekli değişkenlerin birbirleri arasındaki ilişki Spearman korelasyon testi kullanılarak analiz edilmiştir. Alt ekstremite osteoartritlerinde kullanılan nonfarmakolojik tedavi yaklaşımlarını ölçen 12 sorunun iç tutarlılığının belirlenmesinde ise Cronbach Alfa çözümlemesi yöntemi kullanılmıștır ve Cronbach Alpha iç tutarlılık katsayısı 0,85 olarak hesaplanmıştır. Çalışmada istatistiksel anlamlılık düzeyi p<0,05 olarak kabul edilmiştir.

\section{Bulgular}

Çalışmamıza 234 gönüllü dahil edilmiştir. Katılımcıların yaş ortalaması 31,76ะ7,74, ortanca yaş 29, en küçük yaş 24 ve en büyük yaş ise 58'dir. Katılımcıların detaylı sosyodemografik bilgileri Tablo 1' de verilmektedir.

Katılımcıların \%48,71'i, çevresinde daha önce osteoartrit teşhisi konmuş yakının olduğunu belirtti.

Çalışmamızdaki katılımcıların \%45,29'u daha önce OA tedavi yaklaşımları konusunda bir eğitim aldıklarını ifade ettiler. Eğitim alınan yerler lisans, uzmanlık eğitimleri ve kongreler olarak belirtildi. Eğitim alan katılımcıların sadece $\% 42,45$ 'i aldıkları eğitimin yeterli olduğunu ifade ettiler.

“Kılavuzlarda alt ekstremite $\mathrm{OA}^{\prime}$ larında ilk tedavi şekli aşağıdakilerden hangisidir?" sorusuna katılımcıların \%88,00'i doğru seçenek olan "farmakolojik ve nonfarmakolojik" cevabını verdiler.

"OA tanısı koyduğunuz hastalarınıza yaklaşımınız nasıldır?" sorusuna ise katılımcıların çoğunluğu yani \%48,29’u "nonfarmakolojik yöntemleri önerme cevabını vermişlerdir.

Katılımcıların "Kendinizi alt ekstremite $O A^{\prime}$ ları yönetimi konusunda ne kadar yetkin ve donanımlı hissediyorsunuz?" sorusuna verdikleri cevaplar Şekil 1' de gösterilmiștir. Hekimlerin alt ekstremite OA' ları konusunda kendilerine verdikleri yetkinlik puanının ortancası 5 olmuştur.

Daha önce OA tedavi yaklaşımları konusunda herhangi bir eğitim almış olan hekimlerin kendilerine verdikleri yetkinlik puanı, eğitim almamış olan hekimlerin kendilerine verdikleri puandan anlamlı olarak daha yüksek bulunmuştur $(p<0,001)$. Ayrıca bu eğitimin yeterli olduğunu düşünenlerin kendilerine verdikleri yetkinlik puanı da yeterli olmadığını düşünenlerin kendilerine verdikleri puandan anlamlı olarak daha yüksek bulunmuştur $(\mathrm{p}<0,001)$. 
OA teşhisi konulan yakını olan hekimlerin kendilerine verdikleri yetkinlik puanı $(5,33 \pm 1,51)$, OA teşhisi konulan yakını olmayan hekimlerin kendilerine verdikleri puandan $(4,91 \pm 1,37)$ anlamlı olarak daha yüksek $\operatorname{olmuştur}(\mathrm{p}=0,040)$.

Katılımcıların nonfarmakolojik tedavi yöntemlerinin kullanım sıklıklarına göre hesaplanan nonfarmakolojik toplam yaklaşım puanı ortalaması $24,57 \pm 7,63$, ortanca puan 25 , en küçük puan 0 ve en büyük puan 45 olmuştur. OA'larda nonfarmakolojik tedavi toplam yaklaşım puanını veren ve aynı zamanda bu yöntemleri kullanım sıklıklarını gösteren ilgili parametrelere verilen cevapların dağılımı detaylı bir şekilde Tablo 2'de verilmektedir.

Çalışmamızda aldıkları eğitimin yeterli olduğunu belirten katılımcıların nonfarmakolojik toplam yaklaşım puan ortalamaları, aldıkları eğitimin yeterli olmadığını belirten katılımcıların puan ortalamalarından anlamlı olarak daha yüksek bulunmuştur( $\mathrm{p}=0,030)$.

Tablo 1. Katılımcı Aile Hekimlerinin Sosyo-Demografik Özellikleri

\begin{tabular}{|c|c|c|c|c|c|}
\hline Bireysel Özellikler & \multicolumn{2}{|c|}{ Sayı (n) } & \multicolumn{3}{|c|}{ Yüzde (\%) } \\
\hline \multicolumn{6}{|l|}{ Cinsiyet } \\
\hline Kadın & \multicolumn{2}{|c|}{146} & \multicolumn{3}{|c|}{62,39} \\
\hline Erkek & \multicolumn{2}{|c|}{87} & \multicolumn{3}{|c|}{37,17} \\
\hline \multicolumn{6}{|l|}{ Medeni Durum } \\
\hline Bekâr & \multicolumn{2}{|c|}{96} & \multicolumn{3}{|c|}{41,02} \\
\hline Evli & \multicolumn{2}{|c|}{134} & \multicolumn{3}{|c|}{57,26} \\
\hline Boşanmış & \multicolumn{2}{|c|}{4} & \multicolumn{3}{|c|}{1,70} \\
\hline \multicolumn{6}{|l|}{ Mesleki Unvan } \\
\hline Eğitim Görevlisi & \multicolumn{2}{|c|}{8} & \multicolumn{3}{|c|}{3,41} \\
\hline Aile Hekimliği Uzmanı & \multicolumn{2}{|c|}{2} & \multicolumn{3}{|c|}{0,85} \\
\hline Aile Hekimliği Asistanı & \multicolumn{2}{|c|}{165} & \multicolumn{3}{|c|}{70,51} \\
\hline $\begin{array}{lrlr}\text { SAHU (Sözleşmeli } & \text { Aile } & \text { Hekimliği } \\
\text { Uzmanlık Öğrencisi) } & & \\
\end{array}$ & \multicolumn{2}{|c|}{59} & \multicolumn{3}{|c|}{25,21} \\
\hline Yaş (yıl) ve Mesleki Tecrübe & En Küçük & En Büyük & Ortalama & Ortanca & SD \\
\hline Yaş (yll) & 24 & 58 & 31,76 & 29 & 7,74 \\
\hline Mesleki Tecrübe (yıl) & 1 & 31 & 6,89 & 4 & 7,51 \\
\hline
\end{tabular}


Tablo 2. Katılımcı Aile Hekimlerinin Nonfarmakolojik Tedavi Yöntemlerini Kullanım Sıklıkları

\begin{tabular}{|l|c|c|c|c|c|}
\hline $\begin{array}{l}\text { Nonfarmakolojik } \\
\text { tedavi yöntemleri }\end{array}$ & $\begin{array}{c}\text { Hiçbir zaman } \\
\mathbf{n}(\mathbf{\%})\end{array}$ & $\begin{array}{c}\text { Nadiren } \\
\mathbf{n}(\mathbf{\%})\end{array}$ & $\begin{array}{c}\text { Ara sıra } \\
\mathbf{n}(\mathbf{\%})\end{array}$ & $\begin{array}{c}\text { Genellikle } \\
\mathbf{n}(\mathbf{\%})\end{array}$ & $\begin{array}{c}\text { Her zaman } \\
\mathbf{n}\end{array}$ \\
\hline Eğitim & $4(1,70)$ & $6(2,56)$ & $22(9,40)$ & $82(35,04)$ & $\mathbf{1 2 0} \mathbf{5 1 , 2 8}$ \\
\hline Düzenli telefonla arama & $\mathbf{1 4 7}(\mathbf{6 2 , 8 2})$ & $61(26,06)$ & $22(9,40)$ & $4(1,70)$ & $0(0,00)$ \\
\hline $\begin{array}{l}\text { Baston, yürüteç, dizlik, } \\
\text { tabanlık }\end{array}$ & $10(4,27)$ & $46(19,65)$ & $61(26,06)$ & $\mathbf{8 1}(\mathbf{3 4 , 6 1 )}$ & $36(15,38)$ \\
\hline Egzersiz & $6(2,56)$ & $17(7,26)$ & $46(19,65)$ & $\mathbf{9 1 ( 3 8 , 8 8 )}$ & $74(31,62)$ \\
\hline Kilo verme & $1(0,42)$ & $2(0,85)$ & $6((2,56)$ & $69(29,48)$ & $\mathbf{1 5 6}(\mathbf{6 6 , 6 6 )}$ \\
\hline Termal modaliteler & $6(2,56)$ & $23(9,82)$ & $65(27,77)$ & $\mathbf{9 5}(\mathbf{4 0 , 5 9 )}$ & $45(19,23)$ \\
\hline Elektroterapi & $\mathbf{8 7}(\mathbf{3 7 , 1 7})$ & $58(24,78)$ & $58(24,78)$ & $23(9,82)$ & $8(3,41)$ \\
\hline Psikososyal destek & $18(7,69)$ & $32(13,67)$ & $65(27,77)$ & $\mathbf{7 7}(\mathbf{3 2 , 9 0 )}$ & $42(17,94)$ \\
\hline İş-uğraşı terapileri & $35(14,95)$ & $35(14,95)$ & $62(26,49)$ & $\mathbf{6 8}(\mathbf{2 9 , 0 5})$ & $34(14,52)$ \\
\hline Akupunktur & $\mathbf{7 9 ( 3 3 , 7 6 )}$ & $73(31,19)$ & $54(23,07)$ & $23(9,82)$ & $5(2,13)$ \\
\hline Balneoterapi & $45(19,23)$ & $68(29,05)$ & $\mathbf{6 9}(\mathbf{2 9 , 4 8 )}$ & $44(18,80)$ & $8(3,41)$ \\
\hline $\begin{array}{l}\text { Bitkisel ilaçlar- } \\
\text { Fitoterapi }\end{array}$ & $\mathbf{1 1 7}(\mathbf{5 0 , 0 0 )}$ & $69(29,48)$ & $30(12,82)$ & $15(6,41)$ & $3(1,28)$ \\
\hline
\end{tabular}

Koyu ifadeler en çok cevaplanan seçenekleri göstermektedir.

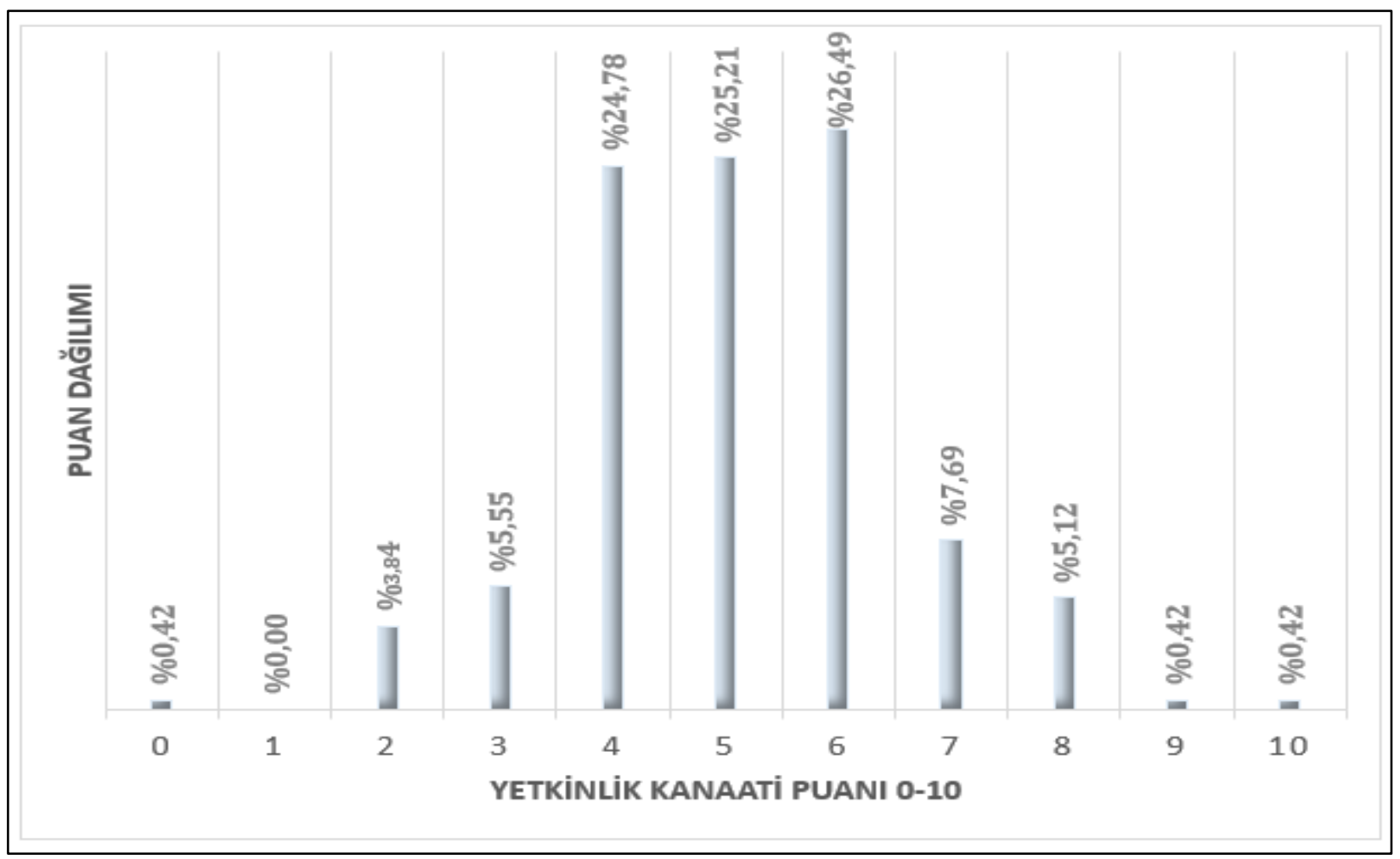

Şekil 1. Katılımcı Aile Hekimlerinin Osteoartrit Yönetimi Konusunda Yetkinlik Kanaatlerinin Dağılımı 


\section{Tartışma}

Aldıkları eğitimin yeterli olduğunu belirten katılımcıların nonfarmakolojik toplam yaklaşım puan ortalamalarının, aldıkları eğitimin yeterli olmadığını belirten katılımcıların puan ortalamalarından anlamlı olarak daha yüksekti. Bu durum alınan eğitim miktarı ve bu eğitime dair yeterlilik kanaati arttıkça nonfarmakolojik yöntemleri kullanma sıklığını da arttırabileceğini düşündürmektedir.

OA teşhisi konulan yakını olan hekimlerin kendilerine verdikleri yetkinlik puanının OA teşhisi konulan yakını olmayan hekimlerin kendilerine verdikleri puandan anlamlı olarak daha yüksek olması da yakın çevresinde OA teşhisi konulan yakını olan hekimlerin bu hastalıkla daha yakından ilgilendiklerini ve yakınlarına faydalı olabilmek, takiplerini yapabilmek adına hastalığı daha çok araştırdıklarını, böylelikle kendilerini daha yetkin hissettiklerini gösteriyor olabilir.

Çalışmamızda eğitim (yaşam stili değişikliği, aktivitelerin takibi, hastalığın seyri) yöntemi yüksek oranda aile hekimleri tarafından hastalarına önerilmiştir. Benzer şekilde Irak'taki birinci basamak hekimlerinin alt ekstremite osteoartritli hastalar hakkındaki tutumlarını incelemek için yaptıkları bir çalışmada da hekimlerin üçte ikisinden fazlasının $(\mathrm{n}=14 ; \% 70,6)$ hastalarını durumları hakkında eğitim verdikleri bulunmuştur. ${ }^{5}$

Çalışmamızda düzenli telefonla arama yöntemini hekimler düşük bir seviyede hastalarına önerdiklerini ifade etmişlerdir. Psikososyal destek yönteminin de hekimler arasında orta seviyede tercih edildiği saptanmıştır. Bunların nedeninin hekimlerin aşırı iş yükü ve zaman azlığı gibi durumlardan kaynaklanabileceği düşünülmüştür. Literatürdeki birinci basamağa yönelik benzer çalışmalarda da bu yöntemlerin plaseboya göre faydası gösterilmesine rağmen yabancı hekimler tarafından düşük bir seviyede hastalarına önerildiği görülmüştür,5,6

Baston, yürüteç gibi yardımcı cihaz yöntemlerinin hekimler tarafından orta seviyede hastalarına önerildiği ifade edilmiştir. Bu oranlar aile hekimlerinin yardımcı cihazlar hakkındaki bilgi eksiklikleri olduğunu düşündürmektedir. Fransa'da ve Irak'ta birinci basamak hekimlerine yönelik yapılan çalışmalarda da benzer oranlar bulunmuştur..$^{5,7}$

Egzersiz yöntemlerini hekimler yüksek oranda hastalarına önermişlerdir. Fransa'da yapılan bir çalışmada

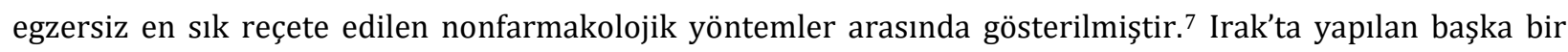
çalışmada Iraklı birinci basamak hekimlerinin \%76,5' inin hastalarına egzersiz önerilerinde bulunduğu görülmüştür. ${ }^{5}$ Bu iki çalışmanın sonucu bizim çalışmamızla benzerdir. 
Çalışmamızda aile hekimleri kilo verme yöntemini hastalarına yüksek bir düzeyde önerdiklerini ifade etmişlerdir. Benzer şekilde Fransa'daki çalışmada \%76,0 oranında genel pratisyenlerin hastalarına kilo vermeyi önerdiği, yine Suudi Arabistan'da yapılan çalışmada birinci basamak hekimlerinin \%79,2 oranında (n:61) kilo vermeyi hastalarına önerdiği görülmüştür.7,8

İskoçya'da yapılan bir çalışmada osteoartrite bağlı kronik diz ağrısı olan hastalarda TENS- transkutan elektriksel sinir stimülasyonu uygulamasını plasebo TENS ile karşılaştırmışlardır. Üçüncü hafta sonunda aktif TENS grubu ağrıda azalma bakımından plasebo grubundan üstün bulunmuştur. ${ }^{9}$ Bizim çalışmamızda ise elektroterapi (TENS) yöntemi düşük düzeyde hekimler tarafından hastalarına önerilmiştir. Bu öneri düşüklüğü aile hekimlerinin bu yöntem hakkındaki bilgi eksikliğinden veya bu yöntemin aile hekimliği branşının alanı olmadığını, fizik tedavi ve rehabilitasyon branşının alanı olduğunu düşünmelerinden kaynaklanıyor olabilir. Ayrıca TENS cihazlarının aile hekimliği kliniklerinde bulunmaması da aile hekimlerinin önerme oranını düşürmüş olabilir.

Akupunktur yönteminden OARSI (Osteoarthritis Research Society International) 2008 kılavuzunda diz OA'yı olan hastalarda semptomatik yarar sağlayabilir şeklinde bahsedilmekte ve kanıt düzeyi Ia olarak belirtilmekte, NICE (National Institue for Health and Care Excellence) kllavuzunda ise önerilmemektedir.10,11 Bizim çalışmamızda akupunktur yönteminin düşük oranda önerildiği ifade edilmiştir. Kılavuzlardaki farklı yaklaşımlara bakarsak bu yöntemin hekimler tarafından düşük düzeyde önerilmesini de açıklayabiliriz. Ayrıca akupunkturun patofizyolojisinin ve sonuçlarının, hekimler tarafından tam anlamıla bilinmiyor olması ve yöntemi uygulamak için sertifika gerektiriyor olması da bu yöntemin önerme ve kullanma oranlarının düşüklüğünü açıklayabilir.

2017 yılında yayınlanan bir metaanalizde, balneolojik tedavinin diz osteoartriti olan hastalarda ağrı, tutukluk ve fonksiyonel durum gibi parametrelerde kontrollere oranla klinik olarak daha etkili olduğu sonucuna varılmıştır. ${ }^{12}$ Çalışmamızda ise aile hekimleri balneoterapi (kaplıca, çamur banyosu) yöntemlerini düşük düzeyde önermişlerdir. Bunun sebebi ülkemizde balneoterapi yöntemlerinin uygulandığı üniversitelerdeki Tıbbi Ekoloji ve Hidroklimatoloji Bölümlerinin az sayıda oluşu ve hekimlerin bu branş hakkındaki bilgi düzeylerinin yetersiz oluşu olabilir. Ayrıca ülkemizde yer alan kaplıcaların çoğunlukla geleneksel, turistik amaçla kullanılan yerler olması hekimlerimizin bu yöntemleri daha az önermelerine ve kullanmalarına sebep olmuş olabilir. Ancak sağlık turizmi açısından kullanım sıklığının artması sevindiricidir.

Çalışmamızda fitoterapi-bitkisel ilaçlar yönteminin ise düşük seviyede önerilmekte olduğu sonucu çıkmıştır. Benzer şekilde Suudi Arabistan'da yapılan çalışmada da birinci basamak hekimlerinin altıda birinden azı (n:12; \%15,6) bitkisel ilaçları hastalarına önermiştir. ${ }^{8}$ 
Sonuç olarak $\mathrm{OA}^{\prime}$ lar konusunda eğitim alanlarla almayanları karşılaştırdığımız zaman eğitim alan ve bu eğitimin yeterli olduğunu düşünen hekimlerin hem nonfarmakolojik toplam yaklaşım puanlarının hem de kendilerine verdikleri yetkinlik kanaat puanlarının anlamlı olarak yüksek olması OA tedavi yaklaşımları konusunda eğitimin önemini ortaya koymuştur. Ancak çalışmamız aynı zamanda bu konudaki eğitim eksikliğinin de var olduğunu göstermiştir.

OA hastalarda yaygın ve yüksek oranda engellilik oluşturabilen ve sağllk sistemlerine büyük maliyetler getiren kronik bir hastalıktır. Bu maliyetlerin önüne geçebilmek için verilecek basit eğitimlerle aile hekimlerinin daha maliyet etkin ve uygulaması kolay olan nonfarmakolojik tedavi yöntemleri hakkındaki farkındalığı arttırılarak sağlık kaynaklarının verimli kullanılması sağlanabilir. Ayrıca çeşitli ülkelerdeki gibi birinci basamakta kullanılabilecek ülkemizde de ulusal bir osteoartrit yaklaşım kılavuzu oluşturulabilir ya da toplumumuza uygun olarak uluslararası kılavuzların Türkçe'ye uyarlaması yapılabilir. Bu çalışma bu alandaki önemli bir gerekliliği de ortaya koymuştur. 


\section{Kaynaklar}

1. Peat G, McCarney R, Croft P. Knee pain and osteoarthritis in older adults: A review of community burden and current use of primary health care. Ann Rheum Dis. 2001;60(2):91-97. (doi:10.1136/ard.60.2.91).

2. Dawson J. Epidemiology of hip and knee pain and its impact on overall health status in older adults. Rheumatology. 2004;43(4):497-504. (doi:10.1093/rheumatology/keh086).

3. Dinçer Ü. Osteoartrit hastalığının tanımı. In: Osteoartrit Tanı, Tedavi ve Rehabilitasyona Güncel Bakış. İstanbul: Zeta Yayıncılık; 2010:1-13.

4. Kirazlı Y. Osteoartrit tanı ve tedavi kılavuzlarına güncel bakış. Turkish Journal of Geriatrics Supplement 4, 2011: 119-125

5. Tawfeeq AK, Abdel T, Rasheed W. Knowledge , attitude and practice regarding osteoarthritis management among physicians of primary health care centers ; Al-rusafa / Baghdad / 2017. 2019;(1):15-25.

6. Allen KD, Oddone EZ, Coffman CJ, et al. Telephone-based self-management of osteoarthritis: A randomized trial. Ann Intern Med. 2010;153(9):570-579. (doi:10.7326/0003-4819-153-9-201011020-00006).

7. Conrozier T, Marre JP, Payen-Champenois C, Vignon E. National survey on the non-pharmacological modalities prescribed by French general practitioners in the treatment of lower limb (knee and hip) osteoarthritis. Adherence to the EULAR recommendations and factors influencing adherence. Clin Exp Rheumatol. 2008;26(5):793-798.

8. Homoud AH. Knowledge, attitude, and practice of primary health care physicians in the management of osteoarthritis in Al-Jouf province, Saudi Arabia. Niger Med J. 2012;53(4):213. (doi:10.4103/03001652.107556).

9. Lewis D, Lewis B, Sturrock RD. Transcutaneous electrical nerve stimulation in osteoarthrosis: A therapeutic alternative? Ann Rheum Dis. 1984;43(1):47-49. (doi:10.1136/ard.43.1.47).

10. Çeliker R. Kalça ve diz osteoartriti tedavisinde güncel kllavuzlar. Hacettepe TiDergísi. 2008;39:36-44.

11. Zhang W, Moskowitz RW, Nuki G, et al. OARSI recommendations for the management of hip and knee osteoarthritis, Part II: OARSI evidence-based, expert consensus guidelines. Osteoarthr Cartil. 2008;16(2):137-162. (doi:10.1016/j.joca.2007.12.013). 


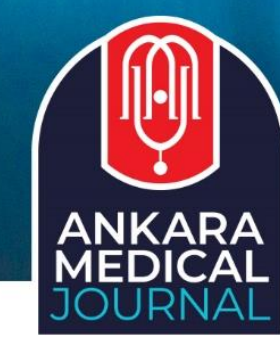

12. Matsumoto H, Hagino $\mathrm{H}$, Hayashi $\mathrm{K}$, et al. The effect of balneotherapy on pain relief, stiffness, and physical function in patients with osteoarthritis of the knee: a meta-analysis. Clin Rheumatol. 2017;36(8):1839-1847. (doi:10.1007/s10067-017-3592-y). 